\title{
Fine-scale genetic structure of grape phylloxera from the roots and leaves of Vitis
}

\author{
AM Corrie and AA Hoffmann \\ Centre for Environmental Stress and Adaptation Research, La Trobe University, Bundoora, Vic. 3086, Australia
}

\begin{abstract}
Patterns of variation at microsatellite loci suggest that root populations of the pest grape phylloxera (Daktulosphaira vitifoliae) are largely parthenogenetic in Australian vineyards. To investigate reproduction in leaf galling phylloxera and the association between these individuals and phylloxera on roots, we examined in detail genetic variation in phylloxera from a vineyard block. Some genotypes found on leaf galls within this block were not present on roots, whereas others spanned both zones. There was no evidence that genotypes on roots were the product of sexual reproduction in leaf galls. mtDNA variation was not associated with the location of the phylloxera clones. The spatial distribution of genotypes
\end{abstract}

within a root population was further investigated by intensively sampling phylloxera from another vineyard block. Joincount spatial autocorrelation statistics were used to explore fine-scale spatial structure. Clones were nonrandomly distributed within the block and there was evidence that the distribution of clones followed rows. These findings suggest firstly that there is limited dispersal of root and leaf feeding phylloxera, and secondly that factors, other than vine host, are likely to be important and contribute to clonal structure within populations.

Heredity (2004) 92, 118-127, advance online publication, 17 December 2003; doi:10.1038/sj.hdy.6800393

Keywords: phylloxera; aphids; microsatellite; parthenogenesis; spatial autocorrelation

\section{Introduction}

Grape phylloxera, Daktulosphaira vitifoliae Fitch (Hemiptera: Phylloxeridae), feeds and forms galls on the leaves and roots of the grapevine (Vitis L.) (Vitaceae: Vitales), the insect's only host. There are over 50 described species of Vitis and several occur within grape phylloxera's indigenous range in North America (Bailey, 1934; Downie et al, 2000). The pest status of this insect was recognized when it was accidentally introduced to commercial vineyards of Europe. The Eurasia grapevine $V$. vinifera was quickly found to be susceptible to root feeding by grape phylloxera and widespread vine decline and death resulted. Resistant rootstocks, derived from American Vitis species, were subsequently bred and are now used extensively in commercial vineyards worldwide.

The Phylloxeridae belong to the superfamily Aphidoidea (Aphids) (Hemiptera: Sternorrhyncha). A threefamily system is used to describe the Aphidoidea and, in addition to the Phylloxeridae, includes the Aphididae and Adelgidae (Blackman and Eastop, 1984). Aphidoidea life cycles incorporate various mating systems, but common to all is apomictic parthenogenetic reproduction. The suppression of meiosis during oogenesis results in offspring that are expected to be genetically identical to their parent (Hales et al, 1997, 2002). Holocycly (cyclic parthenogenesis) is the ancestral life cycle of grape phylloxera and members of the Aphidoidea (Hales et al, 1997). Holocycly consists of parthenogenetic reproduc-

Correspondence: AM Corrie, Centre for Environmental Stress and Adaptation Research, La Trobe University, Bundoora, Vic. 3086, Australia.E-mail: A.Corrie@latrobe.edu.au

Received 30 September 2002; accepted 10 October 2003 tion, which typically begins in spring and continues to autumn, followed by an obligate sexual stage. The egg that results from sexual reproduction is able to diapause till the following spring. The life cycle of grape phylloxera, as described by Granett et al (2001), is as follows. The sexual stage occurs in autumn with the production of winged alates by the root population. These winged insects produce sexuals, which subsequently mate and lay an overwintering egg. The female, which emerges the following spring, then moves onto the newly developing leaf tips and establishes the leaf population. Root populations may be re-established by the movement of leaf galling individuals back to the soil or the overwintering of parthenogenetic first instars on the root system.

Although winged alates occur in autumn and sexuals have been observed in laboratory and field situations, a holocyclic life cycle in grape phylloxera has not been confirmed in commercial vineyards (Granett et al, 2001). A version of the holocyclic life cycle has only been observed within the insect's native environment where grape phylloxera feed only on the leaf system of the vine, and sexuals are produced directly from wingless mothers (Downie and Granett, 1998).

Many other life cycle variants have been described in members of the closely related Aphididae family, including the shift of cyclic parthenogenesis to functional/obligate parthenogenetic reproduction (Delmotte et al, 2001; Simon et al, 2002). Codominant molecular markers, such as microsatellites and allozymes, are extensively used to elucidate such modes of reproduction in this family (Sunnucks et al, 1996; Fuller et al, 1999; Wilson et al, 1999, 2002; Haack et al, 2000; Delmotte et al, 2001, 2002). The coexistence of parthenogenetic and cyclic parthenogenetic reproductive modes means 
aphids are proving to be a useful system to study the evolution and maintenance of sexual and asexual reproduction (Simon et al, 2002). Much evidence indicates that the major advantage to sex in aphids, at least in the short term, is ecological; the sexually produced eggs have the ability to withstand cold winter conditions, whereas overwintering parthenogenetic instars are susceptible to cold conditions (reviewed in Simon et al, 2002). Sexual reproduction is therefore predicated to be the major life cycle strategy in cooler climates with obligate parthenogenetic lineages more common in warmer climates (Rispe and Pierre, 1998).

Recently, four microsatellite markers were developed for grape phylloxera to investigate the incidence of sexual and asexual reproduction in commercial vineyards in Australia (Corrie et al, 2002). Genotypic patterns did not support the hypothesis that founders of leaf galls were the products of sexual reproduction between root galling insects (Corrie et al, 2002). Instead, the patterns were consistent with the hypothesis that root populations largely reproduced by parthenogenesis. Moreover, the two most common and widespread genotypes (G1 and G4) were only sampled from the root system, suggesting that they were root galling specialists.

In this paper we extend these findings by considering two questions. Firstly, what is the relationship between leaf and root galling phylloxera? We sampled and genotyped grape phylloxera from a vineyard block where leaf galling was common and directly compared the leaf and root galling samples from the same vine. Both microsatellite markers and mtDNA sequence data were characterized for these samples. Since leaf galls are usually found on vines derived from North American Vitis species, such as rootstock suckers and direct hybrid producers, sampling was undertaken in vines where there were abundant suckers for the production of galls.

Secondly, what is the spatial distribution of genotypes within a vineyard block? We tested if lineages are randomly distributed or if there is spatial structure within a block. Insects were collected from the roots of two vineyard blocks in which asexual lineages were known to be present (Corrie et al, 2002). Clone diversity was determined by microsatellite analysis, and a joincount spatial autocorrelation approach (Cliff and Ord, 1981; Epperson, 1993) was used to test for spatial patterns. Unlike classical approaches used to study genetic structure within populations, ie F-statistics, join-count spatial autocorrelation statistics enable the actual sampled distribution of individual genotypes to be examined, make fewer assumptions about the underlying population genetic structure, and have a relatively higher level of statistical power enabling the detection of genetic structure on a fine spatial scale (see Cliff and Ord, 1981; Epperson, 1993; Epperson and Li, 1997). For organisms that reproduce clonally, or undergo clonal growth as part of their life cycle, data comprised of individual/multilocus genotypes can be used to test for spatial patterns with the join-count approach. Inferences may then be made about clonal growth and the influence of evolutionary processes on spatial patterns of genetic diversity (Epperson and Li, 1997; Chung and Epperson, 1999; Reusch et al, 1999). Measurements of grape phylloxera spread in Australia suggest a yearly natural dispersal range between 15 and $27 \mathrm{~m}$ (King and Buchanan, 1986), while the spread of a phylloxera infestation is typically described as circular, radiating from an epicentre (Granett et al, 2001). We therefore anticipated that any nonrandom distribution of multilocus genotypes would be short lived unless factors such as microhabitat associations or competitive exclusion influenced phylloxera clonal patterns. The applied as well as evolutionary implications of these results are discussed.

\section{Methodology}

\section{D. vitifoliae sample collection and microsatellite amplification}

Two vineyards, which exhibited leaf galls in the year prior to this study (Corrie et al, 2002), were examined for the presence of leaf galls during December-January 2001. Leaf galls were only observed at one site restricting the leaf galling experiment to a single vineyard located in Glenrowan in northeastern Victoria, Australia (designated as GR-1 block A). To examine the spatial distribution of genotypic classes present on the roots, insects were intensively sampled from the roots of this vineyard and another located in Rutherglen in northeastern Victoria, Australia (RU-1 block A). To enable patterns of genotypic distribution to be examined on a microgeographic scale, the presence of multiple lineages of grape phylloxera at the study sites was required. Previous sampling revealed the presence of several $(\geq 7)$ multilocus genotypes at each site (Corrie et al, 2002).

Insects were collected from a $200 \mathrm{~m} \times 140 \mathrm{~m}$ area within GR-1 block A in the period of phylloxera population growth (January-March 2001). The vineyard block was comprised of the cultivar Shiraz ( $V$. vinifera) grafted to unknown rootstock varieties. Rootstock suckers were common but leaf galls were only observed on some vines. Insects were collected from the roots and leaves of these vines and from the roots of another 119 grapevines located in the same block. Figure 1 illustrates the spatial distribution of the vines and Table 2 provides the location of leaf galling vines. Leaf samples comprised an insect collected from a single gall from up to five leaves per vine. Root samples were collected by digging around the trunk of the grapevine (to a maximum depth of $30 \mathrm{~cm}$ ) and by excising infested roots. Insects were then stored in $100 \%$ ethanol at $-20^{\circ} \mathrm{C}$. For each vine that exhibited leaf galls, five individuals from leaves and two individuals from the root system were DNA typed using four microsatellite loci (DVIT1, DVIT2, DVIT3 and DVIT4). DNA extractions, PCR amplification and characterization of the four microsatellite loci follow Corrie et al (2002). For all other vine samples, a single insect was DNA typed. The terms genotypic class and clonal lineage are used interchangeably to describe the limited number of four locus genotypes evident from the microsatellite patterns.

Insects were collected in February-March 2001 from RU-1 block A. The vines sampled were all grafted to rootstock ARG1 (syn. $\mathrm{A} \times \mathrm{R} \# 1)(V$. vinifera var. Aramon $\times V$. rupestris Ganzin). Insects were collected from the roots of vines located in every third row and from three to five vines per row. Vines sampled along rows were approximately $35 \mathrm{~m}$ apart, while the closest samples collected between rows were $10 \mathrm{~m}$ apart (Figure 2). Root samples were collected by digging 


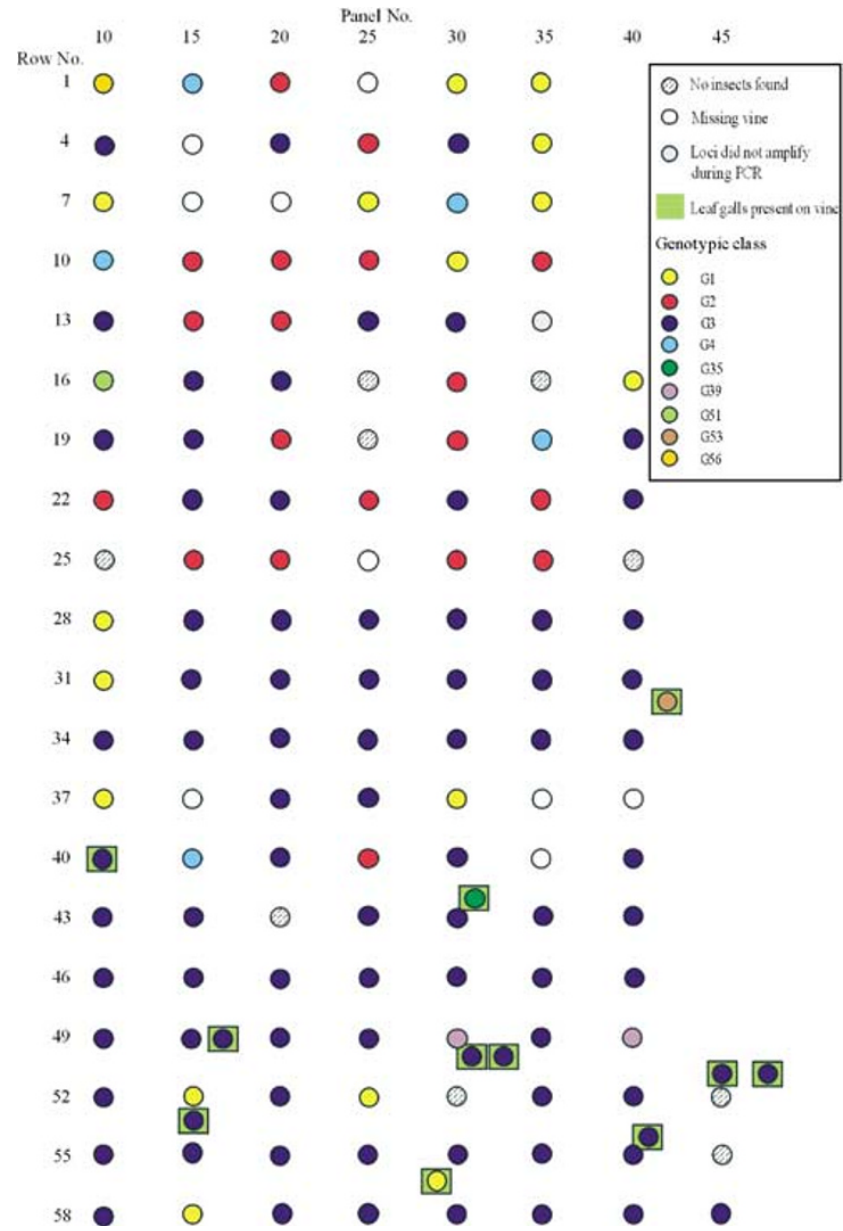

Figure 1 Spatial distribution of Daktulosphaira vitifoliae genotypic classes sourced from the roots of vines in the vineyard GR-1 (block A). One insect per vine was DNA typed and assigned to a genotypic class (see Table 1). Insects were collected from one vine in every fifth panel (approximately every 15th vine) and from every third row. A panel was comprised of three vines. Since rows differed in length, the number of panels collected per row varied from six (rows 1-7) to seven (7-49) and eight panels (52-58). The approximate distance between vine samples was $22 \mathrm{~m}$ along rows and $9 \mathrm{~m}$ between rows. Two insects were also collected and DNA typed from the roots of grapevines with leaf galls. The location of the leaf galling vines and details of leaf collections are provided in Table 2.

around the trunk of the vine until insects were located, or else to a maximum depth of $40 \mathrm{~cm}$. Roots identified as infested were excised, and insects were later removed with the assistance of a binocular microscope. A single insect was DNA typed from each vine.

Root pieces were collected from vines sampled at both sites and DNA typed using five microsatellite loci: VVS2, VVMD6, VVMD7, VVMD28, VVMD31 (Thomas and Scott, 1993; Bowers et al, 1996, 1999). The root pieces were frozen and transported in liquid nitrogen and stored at $-80^{\circ} \mathrm{C}$ prior to DNA extraction. DNA extractions were carried out using DNAzol ${ }^{\mathbb{R}} \mathrm{ES}$ (Molecular Research Centre, USA) according to the manufacturer's instructions. PCR amplification conditions used were as described in Lin and Walker (1998).

DNA typing of 100 Vitis samples confirmed the homogenous composition of RU-1 block A, but demonstrated that GR-1 block A was comprised of several $(\geq 7)$ rootstock varieties (data not shown). Also, within GR-1 block $\mathrm{A}$, the rootstock composition within and across rows was found to be highly variable. This means that the influence of natural dispersal and environmental factors on genotypic distribution patterns cannot be separated from vine host factors, nor can vine host associations be examined unless the Vitis genotype was determined for all vines present in this vineyard block. As a result, only data from the RU-1 block A were used to examine the spatial distribution of root multilocus genotypes.

Mitochondrial DNA sequencing and analysis

To examine the genetic relationship between leaf and root multilocus genotypes, a $426 \mathrm{bp}$ partial sequence of the mitochondrial gene cytochrome oxidase subunit I (COI) was obtained from representatives of each genotypic class. For comparison, an additional 11 leaf galling genotypic classes were sequenced. These genotypic classes were sampled and identified the previous summer from two other vineyards at Milawa (vineyard code ML-1) and Rutherglen (vineyard code RU-13) in northeastern Victoria (refer to Table 6 in Corrie et al, 2002). The primers C1-J-1751 and C1-N-2191 (Simon et al, 1994) were used. PCR amplification was carried out in a $25 \mu \mathrm{l}$ volume using the premixed Ready-To-Go ${ }^{\mathrm{TM}}$ PCR bead kit (Amersham Biosciences, UK). The following temperature profile was used: initial denaturation at $94^{\circ} \mathrm{C}$ for $4 \mathrm{~min}$ was followed by $94^{\circ} \mathrm{C}, 30 \mathrm{~s} ; 50^{\circ} \mathrm{C}, 30 \mathrm{~s}$; and $72{ }^{\circ} \mathrm{C}, 30 \mathrm{~s}$ for 30 cycles. PCR products were cleaned using Wizard PCR Prep Kit (Promega, USA). All templates were sequenced in both directions using the ABI PRISM $^{\mathrm{TM}}$ Big Dye ${ }^{\mathrm{TM}}$ Terminator Cycle Sequencing Ready Reaction Kit according to the manufacturer's instructions (Perkin Elmer Applied Biosystems, USA). Electrophoresis was performed using the ABI PRISM 377 automated sequencer (Perkin Elmer Applied Biosystems, USA). The programs Sequencer ${ }^{\mathrm{TM}}$ version 3.1.2 (Gene Codes Corporation) and ClustalX (Thompson et al, 1997) were used to check and align the sequence data, respectively. Distance (neighbourhood-joining) phylogenetic analysis was conducted using the program MEGA version 2.1 (Kumar et al, 2001) by the two-parameter method (Kimura, 1980). Bootstrap tests were performed with 1000 iterations. In addition to the mitochondrial haplotypes identified in this study, seven COI sequences were incorporated into the phylogenetic analysis (Genbank accession numbers: AF307379; AF307382; AF307386; AF307388; AF307429; AF307434; and AF307437). These represent a subset of the sequences used in a phylogenetic study by Downie et al (2001). The sequences were from leaf galling insects collected from three vine species, $V$. riparia Michaux, $V$. cinerea Englemann and $V$. vulpina L., within the native range of phylloxera in eastern USA. The species $V$. riparia is common in northeast USA, while the ranges of $V$. vulpinia and $V$. cinerea extend from central USA to the east coast (Downie et al, 2001).

\section{Analysis}

To test if genotypic classes were distributed randomly in the root and leaf components in the GR-1 vineyard, we undertook a contingency analysis and computed the 
significance of the likelihood ratio by Monte Carlo simulation using SPSS version 11 .

To test if clonal lineages were randomly distributed within RU-1 block A, a spatial autocorrelation approach for nominal data involving join-count statistics (Cliff and Ord, 1981; Epperson, 1993) was followed. The standardized $z$-value test statistic was determined for like-joins (joins between individuals of the same genotypic class) of 20 and $10 \mathrm{~m}$ distance classes. Under the null hypothesis of a random association, this statistic follows a normal distribution. Significant positive $z$-values indicate more like-joins than expected by chance, and significant negative values indicate dispersion.

Like-joins were only determined for genotypic classes sampled at a frequency of $5 \%$ or greater, which included G12, G19 and G36. In all, 12 Euclidean distance classes in $20 \mathrm{~m}$ units up to $240 \mathrm{~m}$ were tested. Higher classes were not used because there was more than one unconnected locality. In the distance range $0-60 \mathrm{~m}$, $z$-values were computed for smaller $10 \mathrm{~m}$ units to assess the extent of clonal growth between rows versus along rows (as the shortest distance between rows was $10 \mathrm{~m}$, compared to $35 \mathrm{~m}$ within rows). Thus, the distance classes $0-10,0-20$ and $0-30 \mathrm{~m}$ examine the joins between samples in close proximity but located in different rows, whereas the distance class $30-40 \mathrm{~m}$ incorporates joins along rows. Spatial correlograms, comprised of $z$-values graphed against the distance classes, indicated spatial patterns (Figure 3). The analyses were undertaken using the program SpaceStat Version 8.0 (Anselin, 1995).

\section{Results}

\section{Leaf galling study}

All vines in the GR-1 block were checked for rootstock suckering and leaf galls in January 2001. Rootstock suckers were present on approximately $5 \%(\sim 350)$ of the vines, but leaf gall establishment was limited to only 11 of these. Insects were found on the root system of the majority of the vines sampled, including all vines from which leaf galls were obtained (Figure 1 and Table 2).

In all, 11 genotypic classes were identified from the 179 leaf gall and root samples (Table 1). The most common was G3 (42.8 and $64.6 \%$ of the total leaf and root samples, respectively). Genotypic classes were not randomly distributed across leaves and roots as the likelihood ratio was highly significant $(G=83.46, P<0.001$ by Monte Carlo simulation). Five of the seven classes sampled from leaf galls were detected only once or not at all from the root system (Table 1). Two of these (G35 and G54) were sampled from leaf galls on multiple and nonadjacent vines (Table 2). Four other genotypic classes were sampled exclusively from the root system. These included G1 and G4, which had been sampled in this vineyard block from the root system the previous year (Corrie et al, 2002). The most common leaf and root galling multilocus genotype, G3, was also sampled from this vineyard the previous year (Corrie et al, 2002). The temporal persistence of this genotypic class in both the root and leaf galling populations and the occurrence of G3 on multiple leaf galling vines (Table 2) is not the pattern expected if sexual reproduction was required for leaf gall establishment. A more plausible explanation is the clonal spread between the root and leaf systems and the successful overwintering of parthenogenetic insects.

The 11 genotypic classes fell into three mitochondrial haplotypes (Table 1). Five of the seven genotypic classes sourced from leaf galls were defined as haplotype B. This mitochondrial haplotype was also found in 11 leaf galling genotypic classes sourced from two other vineyards, ML-1 (two out of seven sequenced insects) and RU-13 (all nine sequenced insects). An additional haplotype (D - five out of seven insects) was sampled from leaf galls at ML-1. Only a single base pair change differentiated haplotypes $\mathrm{B}$ and $\mathrm{D}$ (Table 3). The

Table 1 Genotypic classes, total number of each genotypic class sampled, allelic profiles and mitochondrial haplotypes of Daktulosphaira vitifoliae sampled from leaves and/or roots of grapevines in the vineyard GR-1. The genotypic classes are based on the pattern of DNA fragment sizes (bp's) at the four microsatellite loci DVIT1, DVIT2, DVIT3, DVIT4. Up to five insects per vine were DNA typed from leaf galls, and one insect per vine from the roots. DNA sequence from the gene cytochrome oxidase I ( $426 \mathrm{bp}$ fragment) was used to define the mitochondrial haplotypes. Refer to Figure 1 and Table 2 for spatial location of the genotypic classes sampled from the roots and leaves respectively and to Table 3 for nucleotide details of each mitochondrial haplotype

\begin{tabular}{|c|c|c|c|c|c|c|c|c|c|c|c|}
\hline \multirow[t]{2}{*}{ Source of insect } & \multirow[t]{2}{*}{ Genotypic class } & \multicolumn{3}{|c|}{ Number of insects } & \multicolumn{4}{|c|}{ Microsatellite genotypes } & \multicolumn{2}{|c|}{ Number sequenced } & \multirow[t]{2}{*}{ Mitochondrial haplotype } \\
\hline & & & & & DVIT1 & DVIT2 & DVIT3 & DVIT4 & & & \\
\hline \multirow{3}{*}{ Leaf only } & & Leaf & Root & Total & & & & & Leaf & Root & \\
\hline & G52 & 3 & - & 3 & $128 / 136$ & $259 / 261$ & $175 / 175$ & $156 / 159$ & 2 & - & C \\
\hline & G54 & 9 & - & 9 & $136 / 136$ & $259 / 261$ & $175 / 175$ & $156 / 156$ & 2 & - & B \\
\hline \multirow{5}{*}{ Leaf \& Root } & G2 & 1 & 19 & 20 & $134 / 136$ & $261 / 261$ & $175 / 175$ & $156 / 156$ & 1 & 2 & B \\
\hline & G3 & 21 & 84 & 105 & $134 / 136$ & $259 / 261$ & $175 / 175$ & $156 / 156$ & 2 & 2 & B \\
\hline & G35 & 12 & 1 & 13 & $134 / 136$ & $259 / 259$ & $175 / 175$ & $156 / 156$ & 2 & - & B \\
\hline & G53 & 2 & 1 & 3 & $136 / 136$ & $259 / 261$ & $175 / 190$ & $156 / 159$ & 1 & 1 & $\mathrm{C}$ \\
\hline & G56 & 1 & 1 & 2 & $134 / 134$ & $259 / 259$ & $175 / 175$ & $156 / 156$ & 1 & - & B \\
\hline \multirow{5}{*}{ Root only } & G1 & - & 16 & 16 & $128 / 136$ & $259 / 289$ & $175 / 190$ & $159 / 159$ & - & 2 & C \\
\hline & G4 & - & 5 & 5 & $128 / 136$ & $259 / 289$ & $175 / 190$ & $159 / 168$ & - & 2 & A \\
\hline & G39 & - & 2 & 2 & 134/136 & $259 / 289$ & $175 / 190$ & NA & - & 2 & B \\
\hline & G51 & - & 1 & 1 & $128 / 134$ & $259 / 261$ & $175 / 190$ & $156 / 159$ & - & 1 & C \\
\hline & Total & 49 & 130 & 179 & & & & & & & \\
\hline
\end{tabular}

NA refers to the non-amplification during PCR. 


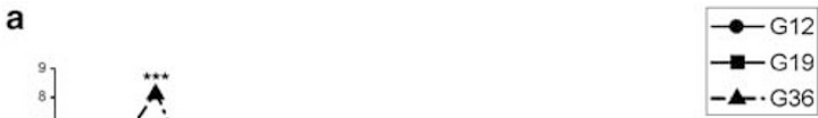
b
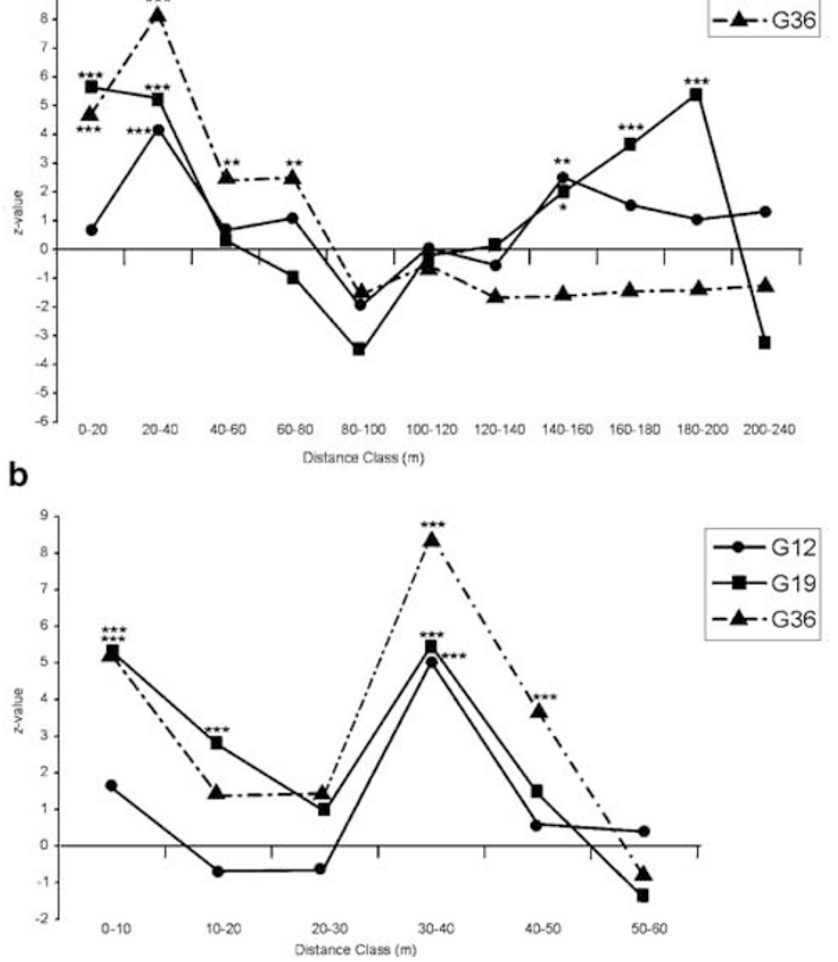

Figure 3 Correlograms plotting the $z$-values of like-joins for three genotypic classes (G12, G19 and G36) of Daktulospharia vitifoliae as a function of Euclidean distance with (a) $20 \mathrm{~m}$ unit distance classes and (b) $10 \mathrm{~m}$ unit distance classes. Refer to Table 4 for details of each genotypic class examined. Significant coefficients are indicated by asterisks: ${ }^{*} P<0.05 ;{ }^{* *} P<0.01 ;{ }^{* * *} P<0.001$.

Figure 2 Map of the spatial study site in the vineyard RU-1 (block A), showing the location of sampled genotypic classes (as described in Table 4). A single insect was DNA typed from each vine sampled. Insects were collected from every third row across 120 rows and three to five vines were sampled per row. All samples were collected from the root system of vine type ARG1. Distances between samples were $35 \mathrm{~m}$ along rows and $10 \mathrm{~m}$ between rows.

haplotypes were found to be identical for a $426 \mathrm{bp}$ region of sequence to those recently defined by Downie (2002) in a worldwide study of mitochondrial haplotype distribution and the same nomenclature was used. Haplotype A comprised one genotypic class (G4), which was sampled solely from the root system. Haplotype C was identified from both the root and leaf samples. Representative insects from the Downie et al (2001) study and the four Australian mitochondrial haplotypes grouped into two clades (Figure 4). The three mitochondrial haplotypes sampled from leaf galls at GR-1, RU-13 and ML-1 all appeared in one clade. There was strong

support for the grouping of these Australian haplotypes and phylloxera sampled from leaf galls on $V$. riparia. Haplotype A belonged to a separate clade alongside phylloxera sampled from $V$. cinerea and $V$. vulpina (Figure 4). The separate grouping of phylloxera sampled from Vitis species common to northeastern USA (V. riparia) to those sampled from Vitis species found in central USA and the east coast region ( $V$. cinerea and V. vulpina) is consistent with Downie et al (2001).

\section{Spatial study}

Insects were collected from the roots of 163 of the 187 vines sampled ( $87 \%$ of vines) but the infestation level was low, with only one or two insects sampled from 67 of these vines ( $41 \%$ of the total infested vines). This is in contrast to other vineyard locations where large colonies of insects can be observed feeding on the root system. Allelic variation was moderate; only one allele was sampled for the DVIT3 locus and two to three alleles for the other three loci (Table 4). Nine genotypic classes were identified. Of these, G19 and G12 were the most frequently sampled and comprised 64 and $18 \%$ of the total samples, respectively. Representatives from each genotypic class were sequenced and identified as haplotype B with one exception, G48, which was identified as haplotype G. Only three synonymous changes distinguished haplotype $G$ from haplotype $B$ 
Table 2 Location details of vines in GR-1 block A that exhibited galling on both the leaf and root component by various genotypic classes of Daktulosphaira vitifoliae. The number of insects of each genotypic class sampled from leaf galls is shown, and the genotypic class of insects sampled from the roots of each vine is indicated in brackets. Refer to Figure 1 for the spatial position of each vine and Table 1 for details of each genotypic class. Samples where one or more loci did not amplify during PCR were not assigned to a genotypic class.

\begin{tabular}{|c|c|c|c|c|c|c|c|c|c|c|}
\hline \multicolumn{6}{|c|}{ Vine location } & \multicolumn{5}{|c|}{ Genotypic class } \\
\hline Row & Panel & G1 & G2 & G3 & G35 & G52 & G53 & G54 & G56 & $N A^{\circ}$ \\
\hline 32 & 42 & - & - & - & - & - & $2(2)$ & 3 & - & - \\
\hline 40 & 10 & - & - & $3(2)$ & - & - & - & - & - & 2 \\
\hline 42 & 31 & - & - & - & $3(2)$ & - & - & - & 1 & 1 \\
\hline 49 & 17 & - & - & $5(2)$ & - & - & - & - & - & - \\
\hline 50 & 31 & - & - & $5(2)$ & - & - & - & - & - & - \\
\hline 50 & 33 & - & 1 & 1 (2) & 1 & - & - & - & - & 2 \\
\hline 51 & 45 & - & - & $-(2)$ & 3 & - & - & 2 & - & 一 \\
\hline 51 & 48 & - & - & 1 (2) & - & - & - & 4 & - & - \\
\hline 53 & 15 & - & - & $5(2)$ & - & - & - & - & - & - \\
\hline 54 & 41 & - & - & $1(2)$ & - & 3 & - & - & - & 1 \\
\hline 56 & 29 & (2) & - & - & 5 & - & - & - & - & - \\
\hline Total & & (2) & 1 & $21(16)$ & $12(2)$ & 3 & $2(2)$ & 9 & 1 & 6 \\
\hline
\end{tabular}

${ }^{a} \mathrm{NA}$ refers to the non-amplification of one or more loci during PCR.

Table 3 Nucleotide states at all positions that are variable in the partial mitochondrial gene $426 \mathrm{bp}$ fragment (cytochrome oxidase subunit I' CO1) for the five Australian Daktulosphaira vitifoliae mitochondrial haplotypes. Note: the five Australian haplotypes sampled in this study were compared to haplotypes recently defined by Downie (2002) and the same nomenclature was used for those identical in sequence for the $426 \mathrm{bp}$ region of COI (haplotype A-D)

\begin{tabular}{|c|c|c|c|c|c|c|c|c|c|c|c|c|c|c|c|c|c|c|c|c|}
\hline & \multicolumn{20}{|c|}{ Nucleotide position } \\
\hline & 7 & 76 & 79 & 82 & 100 & 136 & 190 & 205 & 226 & 235 & 247 & 289 & 296 & 314 & 331 & 367 & 382 & 388 & 389 & 409 \\
\hline Mitochondrial haplotype & $\mathrm{T}$ & $T$ & A & $\mathrm{T}$ & $\mathrm{T}$ & $\mathrm{C}$ & $\mathbf{T}$ & G & $\mathbf{T}$ & G & G & $T$ & G & C & C & G & $\mathbf{T}$ & $T$ & C & $\mathrm{T}$ \\
\hline A & $\mathrm{C}$ & - & - & $\mathrm{C}$ & $\mathrm{C}$ & $\mathrm{T}$ & C & A & $\mathrm{C}$ & $\mathrm{A}$ & A & $\mathrm{C}$ & A & $\mathrm{T}$ & $\mathrm{T}$ & $\mathrm{A}$ & - & $\mathrm{C}$ & $\mathrm{T}$ & $\mathrm{C}$ \\
\hline B & - & - & - & - & - & - & - & - & - & - & - & - & - & - & - & - & - & - & - & - \\
\hline $\mathrm{C}$ & - & C & - & - & - & - & - & - & - & A & - & - & - & $\mathrm{T}$ & - & - & $\mathrm{C}$ & $\mathrm{C}$ & - & - \\
\hline $\mathrm{D}$ & - & - & - & - & - & - & - & - & - & - & - & - & - & $\mathrm{T}$ & - & - & - & - & - & - \\
\hline G & - & - & G & - & - & - & - & - & - & - & - & - & - & $\mathrm{T}$ & - & - & C & - & - & - \\
\hline
\end{tabular}

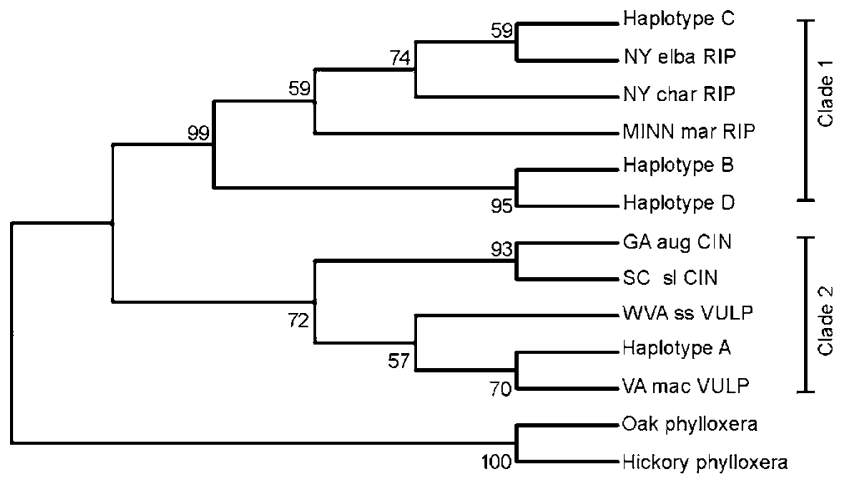

Figure 4 Consensus tree from neighbourhood-joining analysis of Daktulosphaira vitifoliae mitochondrial DNA haplotypes sampled from Australia (haplotypes A, B, C and D) and leaf feeding populations from wild grapevines in northeast USA (New York State (NY char RIP, NY elba RIP) and Minnesota (MINN mar RIP)) and from the central-east coast region (Georgia (GA aug CIN), South Carolina (SC sl CIN), Virginia (VA mac VULP) and West Virginia (WVA ss VULP)). Bootstrap values are shown. Two representatives of other phylloxera species, obtained from oak and hickory, were used as the outgroup species (Downie et al, 2001). Naming of samples from North America follows Downie et al (2001) and includes a state, location and host plant abbreviation (CIN, V. cinerea; RIP, V. riparia; VULP, V. vulpina).
(Table 3). Since there are a limited number of multilocus genotypes and because the reproductive mode during summer is asexual, individuals with identical multilocus profiles are considered to be members of the same clonal lineage (also see the rationale of Sunnucks et al, 1996; Wilson et al, 1999).

Six of the nine genotypic classes identified were sampled from the vineyard RU-1 block A the previous summer (AM Corrie, unpublished data: in brief, insects were collected from the roots of 178 vines during March 2000 from two sections of this vineyard block (vineyard rows 7-15 and 125-140) and DNA typed, revealing the presence of nine genotypic classes - G7, G11, G12, G18, G19, G30, G46, G47 and G48; the genotypic classes G19 and G12 were the most frequently sampled). Excluding the unlikely occurrence of identical multilocus genotypes arising from independent sexual recombination events, the sampling of identical genotypic classes in this vineyard block over two consecutive years implies asexual lineages have overwintered and continued clonal growth the following spring.

Join-count statistics demonstrated that the three most frequently sampled genotypic classes, G19, G12 and G36, were not randomly distributed within the vineyard block. Two significant positive autocorrelation peaks were observed, at the shorter distance classes and then 
Table 4 Genotypic classes, total number of each genotypic class sampled and mitochondrial haplotypes of Daktulosphaira vitifoliae. Insects were sampled from the rootstock ARG1 in the vineyard RU-1 (block A). Refer to Figure 2 for spatial distribution of vines. One insect per vine was DNA typed and assigned to a genotypic class. The allelic combinations of each genotypic class are shown. DNA sequence from the gene cytochrome oxidase I ( $426 \mathrm{bp}$ fragment) was used to define the mitochondrial haplotypes. Refer to Table 3 for details of each haplotype

\begin{tabular}{|c|c|c|c|c|c|c|c|c|}
\hline \multirow[t]{2}{*}{ Genotypic class } & \multirow[t]{2}{*}{ Number sampled } & \multirow[t]{2}{*}{ Relative sample size } & \multicolumn{4}{|c|}{ Microsatellite genotypes } & \multirow[t]{2}{*}{ Number sequenced } & \multirow[t]{2}{*}{ Mitochondrial haplotype } \\
\hline & & & DVIT1 & DVIT2 & DVIT3 & DVIT4 & & \\
\hline G7 & 3 & 0.02 & $134 / 134$ & $259 / 259$ & $175 / 175$ & $156 / 164$ & 1 & B \\
\hline G11 & 3 & 0.02 & $134 / 136$ & $259 / 259$ & $175 / 175$ & $156 / 164$ & 2 & B \\
\hline G12 & 29 & 0.18 & $134 / 136$ & $259 / 261$ & $175 / 175$ & $164 / 164$ & 2 & B \\
\hline G18 & 3 & 0.02 & $134 / 134$ & $261 / 261$ & $175 / 175$ & $164 / 164$ & 2 & B \\
\hline G19 & 105 & 0.64 & $134 / 136$ & $259 / 259$ & $175 / 175$ & $164 / 164$ & 4 & B \\
\hline G26 & 2 & 0.01 & $134 / 134$ & $259 / 259$ & $175 / 175$ & $164 / 164$ & 2 & B \\
\hline G27 & 3 & 0.02 & $136 / 136$ & $261 / 261$ & $175 / 175$ & $164 / 164$ & 1 & B \\
\hline G36 & 8 & 0.05 & $134 / 136$ & $259 / 261$ & $175 / 175$ & $156 / 164$ & 1 & B \\
\hline G48 & 7 & 0.04 & $134 / 136$ & $259 / 261$ & $175 / 175$ & $164 / 167$ & 2 & G \\
\hline Total & 163 & & & & & & 17 & \\
\hline
\end{tabular}

again at distance classes between 140 and $200 \mathrm{~m}$ (Figure 3a). All three genotypic classes showed clustering at $20-40 \mathrm{~m}$, while for the shorter distance class $(0-$ $20 \mathrm{~m}$ ) G19 and G36 were clustered. There was a decrease in $z$-values for all three classes beyond 20-40 $\mathrm{m}$ distance, although G36 continued to demonstrate significant clustering up to $60-80 \mathrm{~m}$. As G36 was only found in rows $64-73$, clustering was not possible past $80-100 \mathrm{~m}$ (Figure 3a). G12 and G19 were associated with a second clustered distribution at 140-160 and 180-200 m, although this trend was stronger for G19 (Figure 3a).

Upon closer examination, using $10 \mathrm{~m}$ distance units, clustering did not appear uniform at the shortest distance classes (Figure 3b). Positive grouping of G19 and G36 individuals was evident at $0-10 \mathrm{~m}$. However, the $z$-value for all genotypic classes was relatively higher at $30-40 \mathrm{~m}$ compared to $10-20$ and $20-30 \mathrm{~m}$, suggesting that clonal distributions followed rows (Figure $3 \mathrm{~b}$ ). The impact of sampling along rows was particularly evident for G12, where no significant clustering was observed when only joins between nearby rows were considered but $z$-values were highly significant at $30-40 \mathrm{~m}$.

While G19 was the most common genotypic class, two patches consisting predominantly of G12 were evident between rows 64-76 and rows 109-127 (Figure 2). The presence of large areas in which G19 was sampled interspaced by two patches in which G19 was largely absent helps to explain the presence of a second area of clustering for G19 at $140-200 \mathrm{~m}$ (Figure 3a). This patchiness also contributes to the second positive autocorrelation peak for G12, although this peak is weaker than that for G19 because of the presence of other genotypic classes.

\section{Discussion}

\section{Reproduction in grape phylloxera}

The leaf gall study suggests that sexual reproduction is not required for leaf gall establishment in spring. Grape phylloxera is believed to have been present in the Glenrowan region prior to the establishment of the sampled vines in the 1920s (Buchanan, 1990). According to local observations, the vines have been infested with leaf galling grape phylloxera for several decades. Due to this long history of infestation, high levels of genetic diversity would be expected if sex is required to establish leaf galls. Indeed, given the allelic diversity present in this vineyard, 648 genotypic classes might be expected from random sexual reproduction. However, only 11 genotypic classes were identified from the 179 insects typed. This low level of genetic diversity is consistent with other studies of predominantly asexual aphid populations (Sunnucks et al, 1996; Wilson et al, 1999; Delmotte et al, 2002). Moreover, the temporal stability of the most common leaf and root galling genotype, G3, suggests the establishment of leaf galls by parthenogenetic insects rather than sexual offspring. The possibility of sexual reproduction between leaf galling genotypes was considered. The evidence did not support sexual reproduction given that there were only seven genotypic classes from galls, that allelic combinations such as DVIT4 ${ }^{159}$ homozygotes were absent, and that identical genotypic classes were sampled from multiple and nonadjacent grapevines. Combining these results suggest that it is likely leaf feeding phylloxera are nonholocyclic, that is, sex is not obligate and is not required for leaf gall establishment in this vineyard block.

The sampling of identical genotypic classes in GR-1 block A and RU-1 block A over two consecutive years supports the contention that root populations of grape phylloxera in Australia are comprised primarily of obligate and/or functionally parthenogenetic clonal lineages, as proposed in Corrie et al (2002). Of the nine genotypic classes sampled from RU-1 block A in 2000, six were seen again the following year. Likewise, the four most common genotypic classes sampled from vine roots from GR-1 block A in 2001 were present in a previous study (see Corrie et al, 2002). In aphid populations, specifically members of the Aphididae, the incidence and distribution of parthenogenetic lineages compared to cyclic parthenogenesis are thought to correspond with climatic conditions (Simon et al, 2002). In general, overwintering parthenogenetic instars are susceptible to cold conditions but sexually produced eggs are cold resistant. However, the relationship between sex and the cold-resistant egg may not be exclusive in the aphids. Although all sexual females lay eggs, the key distinguishing characteristic of the Aphididae is viviparity, ie the production of live young by parthenogenetic females. 
Parthenogenetic and sexual females from the Adeligidae and Phylloxeridae families deposit eggs only (oviparity). Information on the diapause ability and ecological tolerance of eggs produced by females from these two families is not readily available (ie Forneck et al, 2001; Granett et al, 2001; Salom et al, 2001). Still, compared to their viviparous relatives, it is less likely that developmental constraints restrict the evolution of a coldresistant parthenogenetic egg (Rispe and Pierre, 1998; Simon et al, 2002). Possible overwintering asexually produced eggs have been observed on the stems of grapevines in a leaf feeding population of grape phylloxera in Arizona (Kimberling and Price, 1996). By examining the incidence of reproduction modes within grape phylloxera, as well as diapause strategies and the ecological properties of various life stages, there is an opportunity to test the ecological advantage theory of sex maintenance in aphids relative to the importance of evolutionary factors.

\section{Relationship between clonal lineages}

In a previous survey over a large geographic range, leaf galling populations appeared to be partly distinct from root galling populations (Corrie et al, 2002). Differences in the frequency and distribution of clonal lineages on the root and leaf systems were also evident in the present study even though samples were obtained from the same vineyard block (Table 1). Five of the seven leaf galling lineages were seldom sampled from the root system and may be specialized leaf galling genotypes. For example, the G35 lineage was sampled from the leaves of four nonadjacent vines but from the root system of only one vine. However, the most common clonal lineage, G3, formed galls on both the roots and leaves of vine hosts in this vineyard.

Phylogenetic analysis of mitochondrial sequence data was used to infer genetic relationships between clonal lineages. The majority of the leaf galling lineages appear to have a common origin based on the analysis of representative insects from this study and leaf galls at two other locations (Tables 1 and 3, Figure 4, Corrie et al, 2002). However, insects sampled only from root galls appeared in two separate clades (Figure 4). Similar galling characteristics therefore appear to have different evolutionary origins.

What do these data suggest about the origin of the G1 and G4 lineages that are the most common types in Australia and are associated with new infestations of grape phylloxera? Phylogenetic analysis grouped G4 (haplotype A) with phylloxera sampled from leaf galls from grapevines whose range extends from central USA to the east coast. Several grape species in this range, such as $V$. vulpina, are rarely used in commercial breeding programmes (Galet, 1988), and the fact that G4 is restricted to roots in Australia may be due to the absence of suitable hosts. The behaviour of G1 (haplotype C) requires another explanation. Grouping of haplotype $\mathrm{C}$ with phylloxera sampled from leaf galls from $V$. riparia, a Vitis species commonly used in rootstock breeding programmes, suggests that G1 may be exposed to Vitis hybrids with suitable genetic backgrounds for leaf gall formation in commercial vineyards. Indeed several leaf galling classes were haplotype C. However, the fact that G1 is restricted to roots both in this study and in a study by Corrie et al (2002) suggests that it is a root feeding specialist. The data also suggest that mtDNA haplotypes cannot be accurately used to predict the feeding ability.

Mitochondrial sequence data can also be used to compare Australian phylloxera samples with a recent study on the phylogenetic origins of grape phylloxera in commercial vineyards worldwide (Downie, 2002). Downie (2002) sampled 20 haplotypes from commercial vineyards located in several countries. Of these, four are identical in sequence to samples from Australian vineyards (haplotypes A-D) (Corrie et al, 2003). This implies that grape phylloxera found in Australia have polyphyletic origins; they may also have common evolutionary histories with grape phylloxera populations located in vineyards around the world (Corrie et al, 2003). Nevertheless, because there is as much mitochondrial variability within a single vineyard block in Australia as in some countries represented in the Downie (2002) survey, additional surveys of genetic diversity are needed on a worldwide level. Furthermore, the results suggest that representation of samples from both root and leaf populations are required. The source of insects used for DNA typing studies worldwide has primarily been from leaf galling populations (ie Forneck et al, 2000, Downie, 2002), and findings from these samples may not be directly relevant to the worldwide distribution of agriculturally important, ie root feeding, genotypes.

\section{Spatial structure and clonal spread}

Join-count statistics have proved useful for the assessment of clonal growth and local spatial structure in plants (Chung and Epperson, 1999; Reusch et al, 1999), and our data indicate that these statistics can also be used to explore fine-scale spatial patterns in insects. Clonal lineages are clearly nonrandomly distributed within a relatively homogenous host environment. Although we have not investigated the cause of the spatial structure here, it appears that directional clonal spread may influence spatial patterns. The correlograms suggest that clonal spread appears to be elliptical along rows rather than between rows. Vineyard practices could potentially facilitate the movement of insects along rows. For example, insects may be moved by machinery and flood irrigation. Grape phylloxera movement along the root system may also contribute to the spread along rows because vines are spaced such that the root system of one vine intermingles with adjacent vines.

The results are inconsistent with field dispersal studies of grape phylloxera in newly infested vineyards where greater spread across rows rather than along rows has been observed (Wildman et al, 1983; King and Buchanan, 1986). Wind-assisted dispersal has been suggested as an important contributor to the extent and direction of the spread (King and Buchanan, 1986). The contrasting distribution of clonal types along rows may therefore reflect the impact of factors other than initial dispersal on clone distribution, ie fitness differences among clonal lineages for site characters. Replication of this study in other vineyards is also required to determine if the spatial pattern observed is indicative of a general trend or if it is site-specific.

The G1 clone, which is common in most phylloxerainfested areas in Australia (Corrie et al, 2002), was not 
sampled in this study of RU-1 block A. The vineyard operation RU-1 is comprised of another 55 ha of vine plantings from which a number of diverse genotypic classes have been sampled, including G1 (Corrie et al, 2002). No internal vineyard quarantine procedures are used to minimize the spread of phylloxera between vineyard blocks, via the movement of machinery, personnel and plant material, suggesting that G1 could have freely spread throughout the vineyard. The absence of G1 may indicate that it cannot successfully compete with other clonal types in this diverse vineyard block because it is a 'general-purpose genotype' (Lynch, 1984). In a population comprising of genetically diverse clones, the fittest clone(s) for an environment is expected to dominate over time, and genetic variability is therefore predicted to be lower in a homogenous environment (Vrijenhoek, 1979; Weeks and Hoffmann, 1998). Differential fitness on host plants has been noted previously between grape phylloxera populations (Granett et al, 1987; Hawthorne and Via, 1994; Forneck et al, 2002). Most recently, by directly examining the distribution of genotypic classes in vineyards with adjacent rows of different rootstocks, Corrie et al (2003) showed strong associations between grape phylloxera clonal lineages and vine host type within a vineyard. The predominance of G19 may indicate that this clone is adapted to the host ARG1. Fitness comparison and selection experiments will help determine if the observed clonal patterns are indeed the result of specialists and/or host-adapted genotypes.

\section{Concluding remarks}

The results of this study challenge the use of leaf galling sourced populations for the evaluation of rootstock resistance (ie Boubals, 1966; Bouquet, 1983; King and Rilling, 1985) and research purposes worldwide (ie Forneck et al, 2000, 2002; Downie, 2002). Two of the root feeding lineages in this study and a previous one (Corrie et al, 2002), G1 and G4, do not appear to have the ability to form leaf galls in commercial vineyards. As these lineages are the most widespread in Australia and are associated with damage in the most recently infested vineyards, it is important to include them when undertaking experiments on the agricultural impact of phylloxera.

The nonrandom distribution of phylloxera clones within a homogenous host environment raises questions about the impact of interclonal selection versus founder, extinction and re-colonization events on the population structure of grape phylloxera within commercial vineyards. While host factors are known to influence the spatial distribution of clonal lineages (Corrie et al, 2003), other factors are also likely to be important and contribute to genotypic patterns within populations that have been infested for a long time. These factors remain to be elucidated. Fitness comparisons and competition experiments among grape phylloxera clones should help define the role of selection and/or competitive interactions on spatial patterns (Rochat et al, 1999). Testing the same clones under similar field conditions, for example, by field translocation experiments, as well as in the laboratory allows the influence of local environmental conditions on clone fitness to be evaluated (Via, 1990). However, direct field comparisons are restricted to clonal lineages currently found at the same site, due to the potential economic impact of introducing grape phylloxera with different biological attributes to a vineyard. This limits field experiments incorporating both G1 and G4, the most common root multilocus genotypes in Australia, to one vineyard located in Glenrowan, Victoria (GR-1) (Corrie et al, 2002).

\section{Acknowledgements}

We thank Melissa Carew for assistance with sequencing of the mitochondrial region and many colleagues for their help with the collection of samples. The cooperation of the three vineyards involved was very much appreciated. Financial support was provided by the Phylloxera and Grape Industry Board of South Australia, the Department of Natural Resources and Environment, and the Australian Research Council via the SPIRT and Special Research Centre programmes.

\section{References}

Anselin L (1995). SpaceStat, A Software Program for the Analysis of Spatial Data, Version 1.80, Regional Research Institute: West Virginia University, Morgantown, WV.

Bailey LH (1934). The species of grapes peculiar to North America. Gentes Herbarum 3: 151-244.

Blackman RL, Eastop VF (1984). Aphids on the World's Crops: An Identification Guide, John Wiley and Sons: New York.

Boubals D (1966). Étude de la distribution et des causes de la résistance au phylloxéra radicicole chez les vitacées. Ann Amél Plant 16: 145-184.

Bouquet A (1983). Étude de la résistance au phylloxéra radicicole des hybrides Vitis vinifera $\times$ Muscadinia rotundofolia. Vitis 22: 311-323.

Bowers JE, Dangl GS, Meredith CP (1999). Development and characterisation of additional microsatellite DNA markers for grape. Am J Enol Viticult 50: 243-246.

Bowers JE, Dangl GS, Vignani R, Meredith CP (1996). Isolation and characterisation of new polymorphic simple sequence repeat loci in grape (Vitis vinifera L.). Genome 39: 628-633.

Buchanan GA (1990). The distribution, biology and control of grape phylloxera, Daktulosphaira vitifolii (Fitch), in Victoria. PhD Thesis. La Trobe University, Melbourne.

Chung MG, Epperson BK (1999). Spatial genetic structure of clonal and sexual reproduction in populations of Adenophora grandiflora (Campanulaceae). Evolution 53: 1068-1079.

Cliff AD, Ord JK (1981). Spatial Processes: Models and Applications, Pion Ltd: London.

Corrie AM, Crozier RH, van Heeswijck R, Hoffmann AA (2002). Clonal reproduction and population genetic structure of grape phylloxera, Daktulosphaira vitifoliae, in Australia. Heredity 88: 203-211.

Corrie AM, van Heeswijck R, Hoffmann AA (2003). Evidence for host-associated clones of grape phylloxera Daktulosphaira vitifoliae (Hemiptera: Phylloxeridae) in Australia. Bull Entomol Res 93: 193-201.

Delmotte F, Leterme N, Bonhomme J, Rispe C, Simon JC (2001). Multiple routes to asexuality in an aphid species. Phil Trans $R$ Soc Lond B Biol Sci 268: 2291-2299.

Delmotte F, Leterme N, Gauthier JP, Rispe C, Simon JC (2002). Genetic architecture of sexual and asexual populations of the aphid Rhopalosiphum padi based on allozyme and microsatellite markers. Mol Ecol 11: 711-723.

Downie DA (2002). Locating the sources of an invasive pest, grape phylloxera, using a mitochondrial gene genealogy. Mol Ecol 11: 2013-2026.

Downie DA, Fisher JR, Granett J (2001). Grapes, galls and geography: the distribution of nuclear and mitochondrial 
DNA variation across host-plant species and regions in a specialist herbivore. Evolution 55: 1345-1362.

Downie DA, Granett J (1998). A life cycle variation in grape phylloxera Daktulosphaira vitifoliae (Fitch). Southwest Entomol 23: $11-16$.

Downie DA, Granett J, Fisher JR (2000). Distribution and abundance of leaf galling grape phylloxera (Hemiptera: Phylloxeridae) and Vitis species in the central and eastern United States. Environ Entomol 29: 979-986.

Epperson BK (1993). Recent advances in correlation studies of spatial patterns of genetic variation. Evol Biol 27: 95-155.

Epperson BK, Li TQ (1997). Gene dispersal and spatial genetic structure. Evolution 51: 672-681.

Forneck A, Walker MA, Blaich R (2000). Genetic structure of an introduced pest, grape phylloxera (Daktulospaira vitifoliae Fitch), in Europe. Genome 43: 669-678.

Forneck A, Walker MA, Blaich R (2001). An in vitro assessment of phylloxera (Daktulosphaira vitifoliae Fitch) (Hom., Phylloxeridae) life cycle. J App Entomol 125: 443-447.

Forneck A, Walker MA, Blaich R (2002). Ecological and genetic aspects of grape phylloxera Daktulosphaira vitifoliae (Hemiptera: Phylloxeridae) performance on rootstock hosts. Bull Entomol Res 91: 445-451.

Fuller S, Chavigny P, Lapchin L, Vanlerberghe-Masutti F (1999). Variation in clonal diversity in glasshouse infestations of the aphid, Aphis gossypii Glover in southern France. Mol Ecol 8: 1867-1877.

Galet P (1988). Cepages et Vignobles de France, Dehan: Montpellier.

Granett J, Goheen AC, Lider LA, White JJ (1987). Evaluation of grape rootstocks for resistance to type A and type B grape phylloxera. Am J Enol Viticult 38: 298-300.

Granett J, Walker MA, Kocsis L, Omer AD (2001). Biology and management of grape phylloxera. Ann Rev Entomol 46: 387-412.

Haack L, Simon JC, Gauthier JP, Plantegenest M, Dedryver CA (2000). Evidence for predominant clones in a cyclically parthenogenetic organism provided by combined demographic and genetic analyses. Mol Ecol 9: 2055-2066.

Hales DH, Tomiuk J, Wöhrmann K, Sunnucks P (1997). Evolutionary and genetic aspects of aphid biology: a review. Eur I Entomol 94: 1-55.

Hales DF, Wilson ACC, Sloane MA, Simon JC, Le Gallic JF, Sunnucks P (2002). Lack of detectable genetic recombination on the $\mathrm{X}$ chromosome during the parthenogenetic production of female and male aphids. Genetic Res 79: 205-209.

Hawthorne DJ, Via S (1994). Variation in performance on two grape cultivars within and among populations of grape phylloxera from wild and cultivated habitats. Entomol Exp App 70: 63-76.

Kimberling DN, Price PW (1996). Variability in the grape phylloxera preference and performance on canyon grape (Vitis arizonica). Oecologia 107: 553-559.

Kimura M (1980). A simple method for estimating evolutionary rate of base substitutions through comparative studies of nucleotide sequences. J Mol Evol 16: 111-120.

King PD, Buchanan GA (1986). The dispersal of phylloxera crawlers and spread of phylloxera infestations in New Zealand and Australian vineyards. Am J Enol Viticult 37: 26-33.
King PD, Rilling G (1985). Variations in the galling reaction of grapevines: evidence of different phylloxera biotypes and clonal reaction to phylloxera. Vitis 24: 32-42.

Kumar S, Tamura K, Jakobsen IB, Masatoshi N (2001). MEGA2: molecular evolutionary genetics analysis software. Bioinformatics 17: 1244-1245.

Lin H, Walker MA (1998). Identifying grape rootstocks with simple sequence repeat (SSR) DNA markers. Am J Enol Viticult 49: 403-407.

Lynch M (1984). Destabilizing hybridization, general-purpose genotypes and geographic parthenogenesis. Quart Rev Biol 59: 257-290.

Reusch T, Hukriede W, Stam W, Olsen J (1999). Differentiating between clonal growth and limited gene flow using spatial autocorrelation of microsatellites. Heredity 83: 120-126.

Rispe C, Pierre JC (1998). Coexistance between cyclical parthenogens, obligate parthenogens, and intermediates in a fluctuating environment. J Theor Biol 195: 97-110.

Rochat J, Vanlerberghe-Masutti F, Chavigny P, Boll R, Lapchin C (1999). Inter-strain competition and dispersal in aphids: evidence from a greenhouse study. Ecol Entomol 24: 450-464.

Salom SM, Sharov AA, Mays WT, Neal JW (2001). Evaluation of aestival diapause in hemlock woolly adelgid. Environ Entomol 30: 877-882.

Simon CF, Frati A, Beckenbach A, Crespi H, Liu H, Flook P (1994). Evolution, weighting and phylogenetic utility of mitochondrial gene sequences and a compilation of conserved polymerase chain reaction primers. Ann Entomol Soc Am 87: 651-701.

Simon JC, Rispe C, Sunnucks P (2002). Ecology and evolution of sex in aphids. Trends Ecol Evol 17: 34-39.

Sunnucks P, England PR, Taylor AC, Hales DF (1996) Microsatellite and chromosome evolution of parthenogenetic Sitobion aphids in Australia. Genetics 144: 747-756.

Thomas MR, Scott NS (1993). Microsatellite repeats in grapevine reveal DNA polymorphisms when analysed as sequence-tagged sites (STSs). Theor App Genetics 86: 985-990.

Thompson JD, Gibson TJ, Plewniak F, Jeanmougin F, Higgins DG (1997). The ClustalX windows interface: flexible strategies for multiple sequence alignment aided by quality analysis tools. Nucleic Acids Res 24: 4876-4882.

Via S (1990). Ecological genetics and host adaptation in herbivorous insects: the experimental study of evolution in natural and agricultural systems. Ann Rev Entomol 35: 421-426.

Vrijenhoek RC (1979). Factors affecting clonal diversity and coexistence. Am Zool 19: 787-797.

Weeks AR, Hoffmann AA (1998). Intense selection of mite clones in a heterogeneous environment. Evolution 52: 1325-1333.

Wildman WE, Nagaoka RT, Lider LA (1983). Monitoring spread of grape phylloxera by color infrared aerial photography and ground investigation. Am J Enol Viticult 34: 83-94.

Wilson ACC, Sunnucks P, Blackman RL, Hales DF (2002). Microsatellite variation in cyclically parthenogenetic populations of Myzus persicae in south-eastern Australia. Heredity 88: 258-266.

Wilson ACC, Sunnucks P, Hales DF (1999). Microevolution, low clonal diversity and genetic affinites of parthenogenetic Sitobion aphids in New Zealand. Mol Ecol 8: 1655-1666. 